\title{
Closure of an aortoesophageal fistula with an esophageal stent and hemoclip
}

The patient was a 43-year-old man with a history of hypertension and a Stanford type B dissecting aortic aneurysm, which had been managed 9 years previously with an aortoplasty. He was admitted to hospital after 3 weeks of dysphagia for solid food and intermittent substernal discomfort. He had massive bloody vomiting and syncope. An emergent computed tomography (CT) scan showed dilatation of the medio-inferior saccular outpouching at the posterior aortic arch. An aortoesophageal fistula (AEF) was diagnosed and an endovascular stent was placed. An urgent upper gastrointestinal endoscopy revealed fresh blood and necrotic tissue at about $30 \mathrm{~cm}$ from the incisors. A Sengstaken-Blakemore tube was immediately inserted and the bleeding stopped.

A CT scan performed after deployment of the aortic stent-graft showed ongoing extravasation from the thoracic aneurysm $(\bullet$ Fig. 1). We chose to use further palliative treatment with a $10-\mathrm{cm}$ covered selfexpandable esophageal metal stent being placed to cover the fistula. He underwent a chest CT scan with reconstruction 11 days later, which showed good positions for both the aortic and esophageal stents (๑ Fig. 2).

The esophageal stent was removed after an esophagogram showed no evidence of leakage. Upper gastrointestinal endoscopy later identified a hole with some granulation tissue ( $\bullet$ Fig. 3 ) and a hemoclip was used to close the fistula. Follow-up with an upper gastrointestinal endoscopy later demonstrated healing of the defect (๑ Fig. 4).

$\mathrm{AEF}$ is an uncommon disorder that carries a high rate of morbidity and mortality. Thoracic aortic aneurysms account for more than $50 \%$ of the cases [1]. In 1914 , Chiari described a triad of symptoms that included mid-thoracic pain, sentinel upper gastrointestinal hemorrhage, and exsanguination after a brief period [2], all of which were experienced by our patient. Upper gastrointestinal endoscopy may

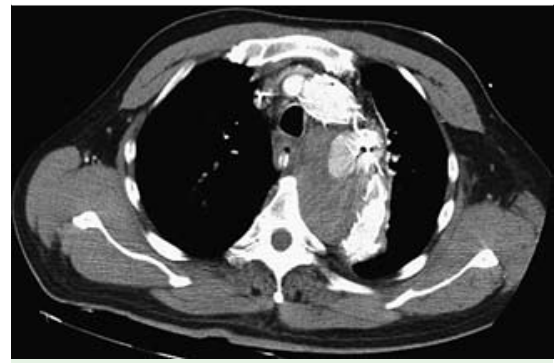

Fig. 1 Computed tomography (CT) scan after insertion of an aortic endovascular stent-graft, demonstrating extravasation from the thoracic aneurysm.

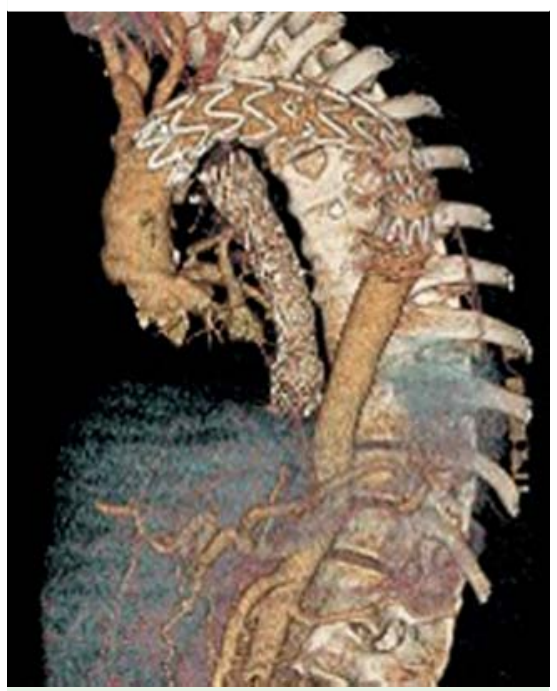

Fig. 2 Computed tomography (CT) scan with reconstruction showing concomitant use of aortic and esophageal stents.

reveal a mass in the esophageal wall and copious amounts of coagulated and fresh blood.

Early diagnosis and accurate localization of the lesions contribute to a better prognosis. Without prompt treatment, this condition is always fatal because of hemorrhage or septic complications. Despite several choices of treatment, little consensus exists on the optimal intervention. Immediate insertion of a SengstakenBlakemore tube for exsanguination offers the chance for further treatment. In pa-

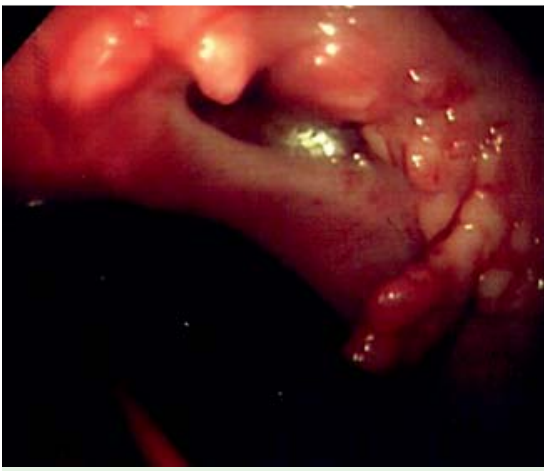

Fig. 3 Upper gastrointestinal endoscopy showing an esophageal defect and granulation tissue $30 \mathrm{~cm}$ distal to the incisors.

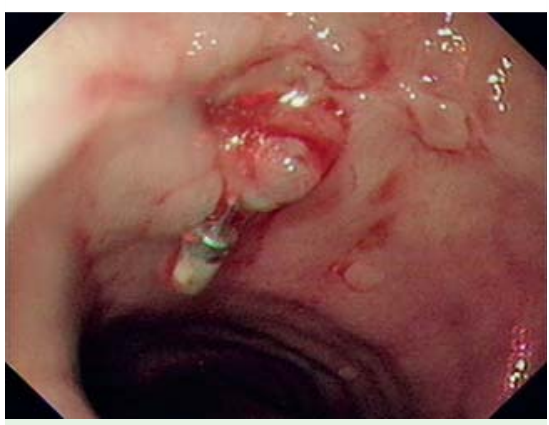

Fig. 4 Upper gastrointestinal endoscopy showing healing of the esophageal defect 20 days after the endoscopic repair.

tients who are high risk for open surgical repair, deployment of an endovascular stent-graft can serve as a palliative or temporary treatment [3]. Recovery of the esophagus may be difficult in AEF. The use of esophageal stenting as a tool for bridging to surgery has also been reported $[4,5]$. In this case, the AEF was treated successfully with an endovascular stentgraft followed by an esophageal stent and hemoclip. No similar cases have been previously reported. Further use of these techniques in the future may validate this result.

\section{Endoscopy_UCTN_Code_TTT_1AO_2AD}

Competing interests: None 
S.-M. Tsai ${ }^{1}$, Y.-Y. Chen ${ }^{1}$, Y. Chin-Yuan ${ }^{1}$, W.-L. Lai $^{2}$

1 Division of Gastroenterology, China Medical University Hospital, Taichung, Taiwan

2 Division of Cardiovascular Surgery, China Medical University Hospital, Taichung, Taiwan

\section{References}

1 Hollander JE, Quick G. Aortoesophageal fistula: a comprehensive review of the literature. Am J Med 1991; 91: 279-287

2 Chiari $H$. Uber Fremdkörperverletzung des Oesophagus mit Aorta perforation. Berl Klin Wochenschr 1914; 51: 7-9

3 Flores J, Shiiya N, Kunihara $T$ et al. Aortoesophageal fistula: alternatives of treatment case report and literature review. Ann Thorac Cardiovasc Surg 2004; 10: 241 - 246

4 Park DH, Park JH, Lee SH. Temporary placement of a covered metal stent for the management of a bleeding aortoesophageal fistula. Endoscopy 2007; 39 (Suppl. 1): E61 E62

5 Zuber-Jerger I, Hempel U, Rockmann F, Klebl F. Temporary stent placement in 2 cases of aortoesophageal fistula. Gastrointest Endosc 2008; 68: 599-602
Bibliography

DOI 10.1055/s-0030-1256525

Endoscopy 2011; 43: E302 -E303

(c) Georg Thieme Verlag KG Stuttgart · New York . ISSN 0013-726X

\section{Corresponding author}

Y.-Y. Chen, MD

China Medical University Hospital

3 Lane 138 Tai-An 2nd Street Changhua 500 Taiwan

Fax: +88-64-7228289

ychen02@gmail.com 